\title{
CINEMA AS A DYNAMIC SYSTEM OF PERCEPTION OF VISUAL IMAGES
}

\section{MARIIA ZVEREVA}

$\mathrm{PhD}$, Researcher,

Department Of Clinical

Moscow, Russia

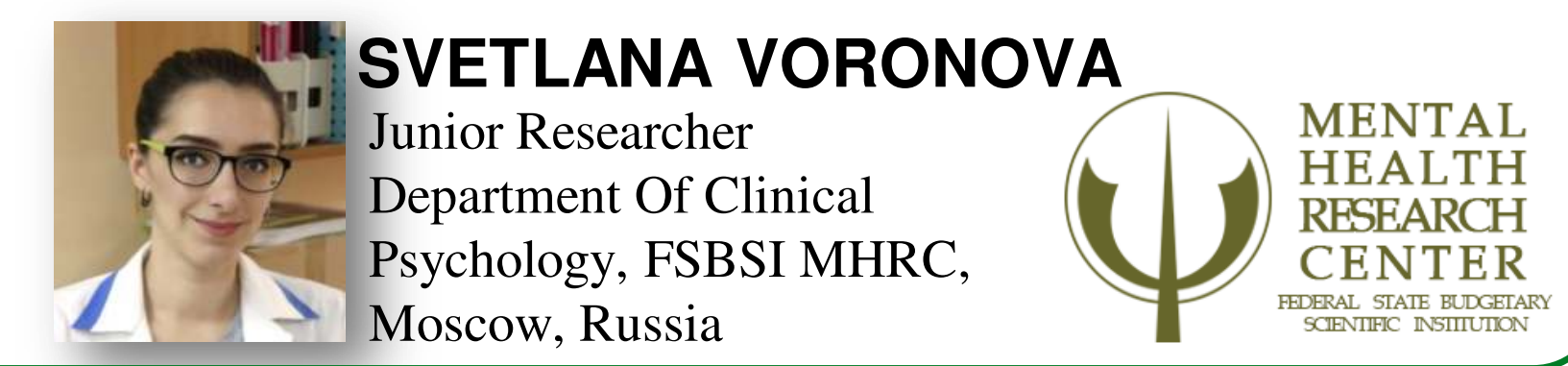

TRODUCTION. Cinema combines two forms: image and text. During process of film perception, there are interaction of film narrative, spectator's personal experience and the cultural and historical context as well. The spectator's understanding of common sense narrative, spectator's personal experience and the cultural and historical context as well. The spectator's understanding of common sense
and everyday realities have an important role in process of film perception. To get an idea of the interaction of simultaneous perception of video sequence and sound, spectator has to be placed in a historical context. General psychological structure of perception could also not be ignored. A simple assessment of the images's visual characteristics reduces the task, turing the variety of perception processes to physical characteristics.

The problem of perception is one of the important problems of the psychology of art. The study of the psychology of art have to begin with two basic elements - feeling and imagination. The correct understanding of the psychology of art can only be created at the intersection of these two problems and is a combined teaching of imagination and feeling in one form or another.

The basis of any aesthetic reaction are the affects experienced by the viewer "realistically" but at the same time related to the activity of fantasy. It is important to note that when experiencing an aesthetic response, the external motor side of affect is suppressed and the person fantasy. It is important to note that when experiencing an aesthetic response, the ex
experiences "ghostly" feelings. All art is based on this unity of feeling and fantasy.

experiences "ghostly" feelings. All art is based on this unity of feeling and fantasy.

The content and the meaning of the film is the result of the complex effect of various factors during viewing, perceived unconsciously and entered by the creator of the film in a specific and thoughtfully time sequence. In theatrical art was introduced the concept of temporhythm by K.S. Stanislavsky. The classical understanding of rhythm is the ratio of movements and stops in space and time. Rhythm is an actions, sounds, feelings of various duration with breaks between them or the correct change of movements, sounds, feelings of differen intensity, flow in time. The rhythm must necessarily have an alternation (sound, movement, feeling), and if the alternation doesn't exist then there is no rhythm. The main role in rhythm is played not by movement, but by accentuation, in other words, stopping or amplification. Without a clear accent rhythm has no clarity or expressiveness, besides, he will not be able to enhance the emotiona coloring of the image. Stanislavsky writes: «Tempo-rhythm mechanically, intuitively or consciously affects our inner life, our feeling and experience... $\langle.\rangle>$. The tempo rhythm of action can intuitively, straight, directly suggest not only the corresponding feeling and excite feelings, but also help creating images». Thus, the tempo-rhythm contributes to the spectator's directed perception of theatrical action. The concept of tempo-rhythm was transferred from theatrical reality to cinema even at the very beginning of its development. One of the firs who used the concept of tempo-rhythm in the cinema was S.M. Eisenstein. Besides, Sergei Eisenstein was among the pioneer of the study of the possibilities of editing in cinema.

AIM. To get an idea of the process of film perception, it's necessary to take into account what functions the film's visual component performed in the system of spectator's views.

METHODS. The main method of cinema is film editing as a way of organizing visual attention. Aims of film editing: capture organization and direction of spectator's sight; focusing of spectator's attention; removal of unnecessary material; drawing spectator's attraction by high-rapid video

DISCUSSION. Process of film perception includes voluntary and involuntary perception. Involuntary attention focuses spectator's sight at something unusial: loud sounds, sudden movements, unusual clothes, etc. Voluntary attention is associated with a spectator's personality: during watching film he relies on his expectations and therefore focuses his attention on those elements of film which interest him. Using cinematographic techniques (such as the "close-up") director transforms spectator's involuntary attention into voluntary: he forces spectator to focus on things he would not pay attention to in normal circumstances. Spectator's attention and perception which were organized by director line up images in space and time in order to discover the point of their interconnection and to take a complete story. Film editing (fr. montage) is a creative and technical process in cinema, on television or recording studios, allowing in a combination of separate fragments of the original records to obtain a single, composite whole work.

The film editing frame (also "film transition", fr. cadre de montage) is the smallest single piece that makes up the film's structure. A series of frames juxtaposed and shown in rapid succession make up a motion picture (film). Several film editing frames form the stage series of frames juxtaposed and shown in rapid succession
set, the stage set forms episode, several episodes form film.

set, the stage set forms episode, several episodes form film.

By mounting filmmakers combine footage in the correct sequence, fulfilling an artistic task and creating the right impression for the viewer. There's a known experiment held by Lev Kuleshov (Figure 1) where the viewer's perception of the same frame with the same actor is different because of the film editing; the perception depends on the previous frame content: a hot plate of soup, a child in a coffin, and a pretty woman lying on a couch

Besides montage, filmmakers use a cinematic shot(s) (field sizes) to convey a cinematic story to the viewer. The size of the shot is determined either by the choice of the lens or by the actual distance from the camera to the filmed object. The distance to the object does not just affect to the understanding of what is happening, it also helps to convey a certain narrative atmosphere or create certain emotions.
For example, proximity or remoteness from actors affects the empathy process of the viewer. The choice of the size of the shot is of key For example, proximity or remoteness from actors affects the empathy process of the viewer. The choice of the size of the shot is of key
importance for the goal-oriented control of the attention of the public and its readiness to identify itself with the characters. In practical filmmaking, a scale of seven (sometimes eight) points was developed to differentiate the distance to the actors (the size of the image of the object). Types of shots are presented in Table 1 and Figure 2 .
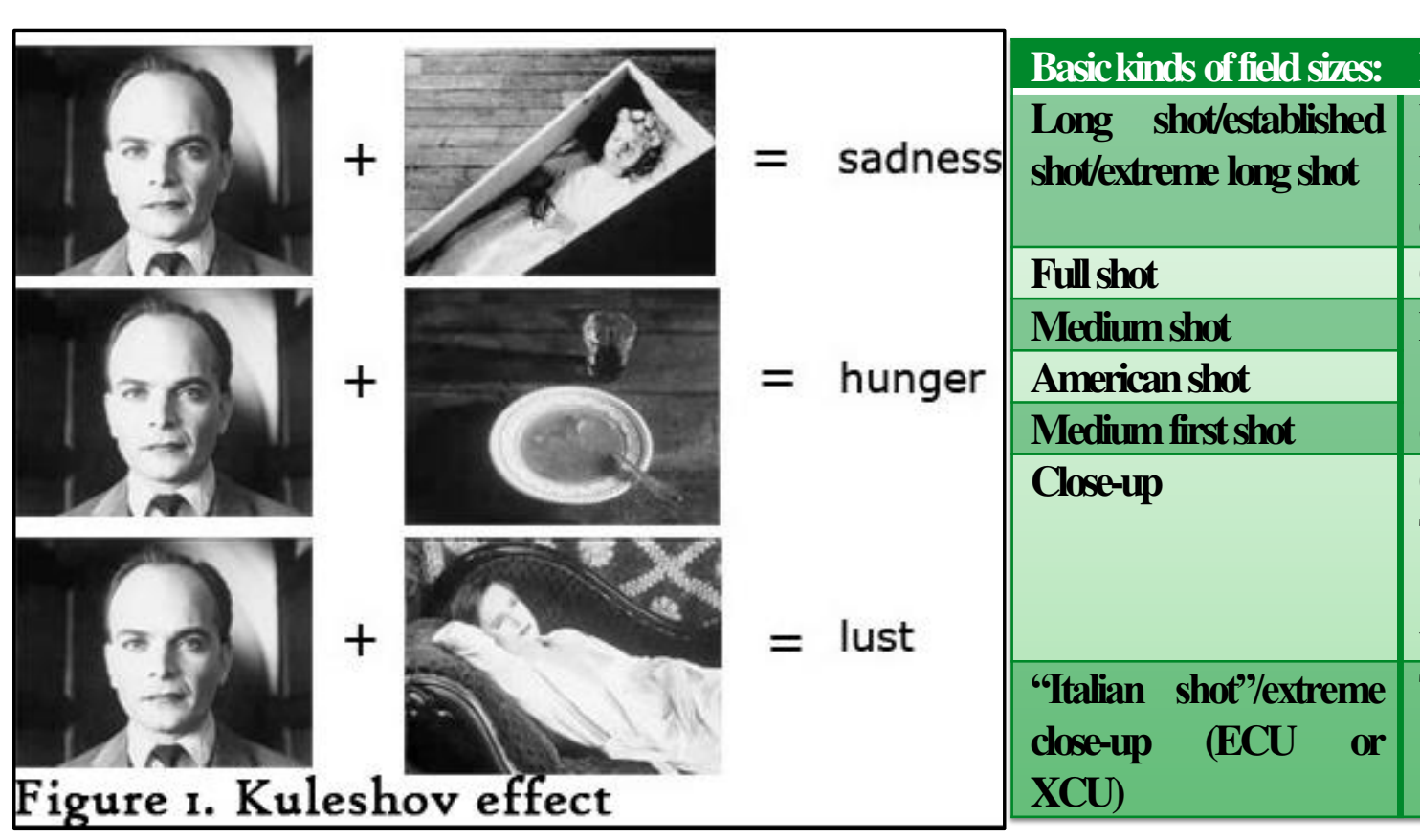

Table 1. Types of shots

ence erspective sow on the suject - but als attention on the most important moment of the narration, to give the viewer a hint to percept the moments of action that are not read from an ordinary point of view.

The rich spatial features are allowing to examine (consider) the scene in depth, to guide the viewer more accurately in the film space, and, most importantly, give the emotional explaining epithet to the events, and also to the character's behavior or their psychological condition. The choice of the set point, the angle of view are always determined by the content of the shooting material and the task the uthor (film director) has set before him. The same feature is also applied to perspective, which focuses the man's eye on the certain point on the screen, guiding the viewer's gaze, and therefore, the story follows in the way the director finds necessary.

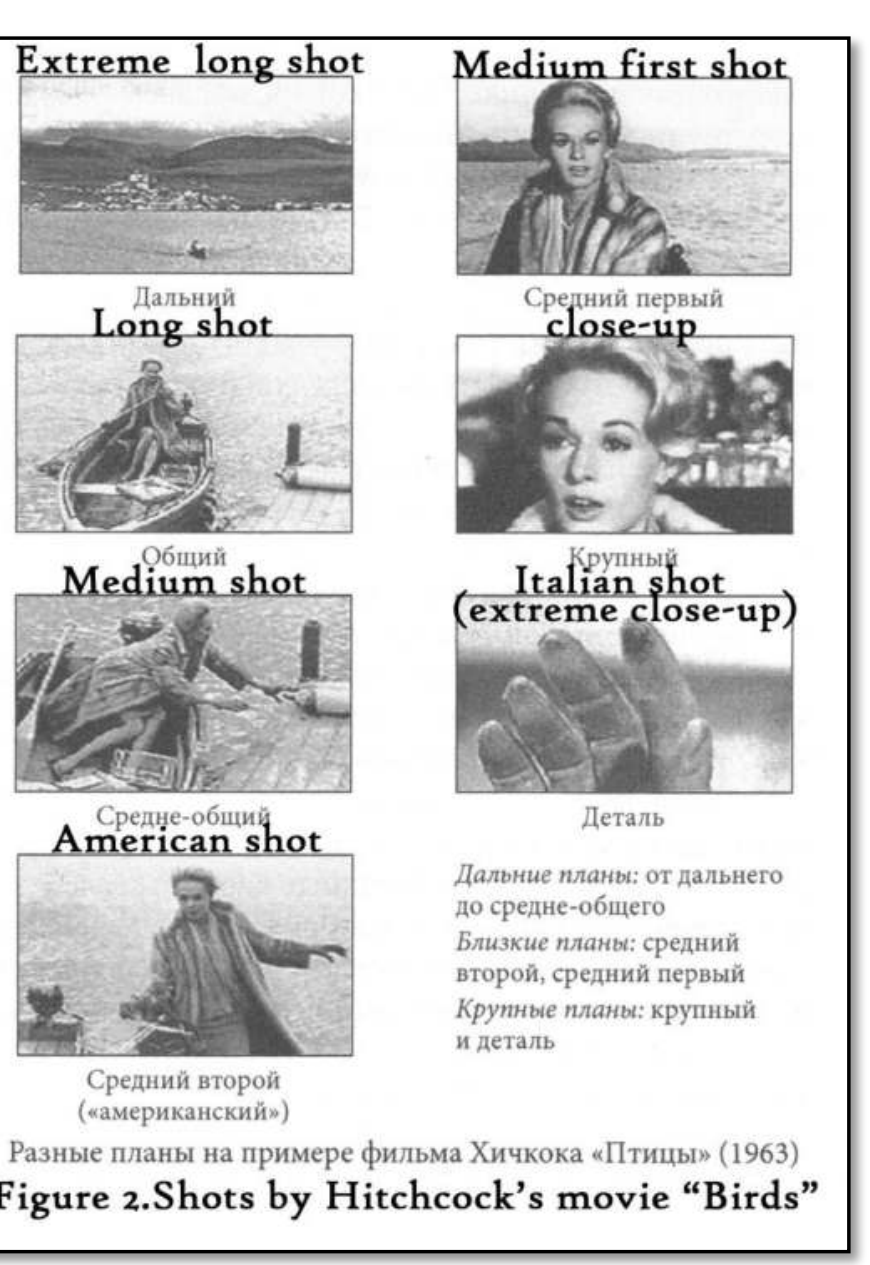

CONCLUSION. The image and its perception have an otherwise status in cinema. Image in cinema is an analogue of sign in cultural-historical psychology, it reveals the symbolic meaning of objects and connections between them in the story. The sign characterizes the causal relationship of things, and the image gives only an idea of them, without using strict causal relationships.

According to Cyril Razlogov, the screen is a kind of "meat grinder of cultural discourse". Cultural discourse is a holistic amount of information. The screen with the help of the montage allows to reprocess the cultural discourse in such a way that when two frames collide, a new meaning is generated - the constructed world. And this is already a concentrate of meaning, which the stage director puts into the film, removing all unnecessary. The spectator, who watches the movie, is led in a certain direction: it seems to him that he sees, even if played by the actors, but reality itself. He feels free. However, cultural discourse is no longer a large and solid "piece of meat" cut by the cameraman from the "body" of the culture, but a purposeful arrangement of a piece that was previously cut and passed through a "meat grinder", which has already been processed into a more or less pseudo-organic body. At the same time it is important to understand that each person has his own individual selectivity of close-ups. Depending on attitude, outlook, personality structure, interests, views, one or another viewer chooses from the surrounding cinema-reality the most significant, in his opinion, moments, details, touches. The message of the film is a construction created jointly by the stage director and the audience with all its individual, situational and socio-historical features. In this case, it turns out that despite the general phenomena of cinema perception and the superficially "driven" role of the viewer, each viewer watches his own (meta) film.

Ejenshtejn SM. Zakadrom Klyucherye raboty potenii kino-M.: Akademicheskij proekt; Gaudeamus, 2016.-727s

Golownya A.D. Masterstro kinooperatora. M., Ikusstvo, 1963

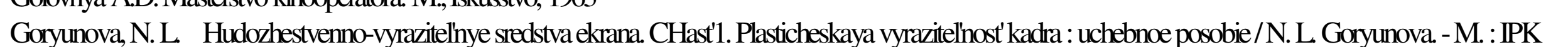
rab.TViRV,2006.-42

Kote G. Vvedenie vsistemnyj kinoanaliz. M. Izd. Dom Vysshej shkoly ekonomiki, 2018. - 360 s.

Razgolov K. Ekran kak myasorubka kulltumogo diskursa. Ekrannaya kultura. Teoreticheskie problemy: sb. statej/Otv. red. K. E. Razlogov.— SPb. «DMITRIJ BULANIN», 2012. S.9-38

6. Stanislavskij K.S. Rabota aktera nad soboj. Vtvorcheskom processe perezhivaniya. Moskva: Eksmo-Press, $2013 \mathrm{~g}$, $-448 \mathrm{~s}$.

Timoshenko S.A. Iskusstvo kino imontazh filma. Poetika kino. Teoneticheskie raboty 1920 hgg. -M: Akademicheskij proekt, Alma Mater, 2016.-S.277-336 Vygotskij L S. Psihologiya iskusstva. Rostov nID: izd-vo 〈Feniks»), 1998.480 